\title{
IMIA's Working Groups and Special Interest Groups
}

\section{Developing the Scientific Knowledge to Build Sustainable Health Systems}

\author{
Peter J. Murray, Guest Editor \\ Centre for Health Informatics Research and Development (CHIRAD), Nocton, Lincolnshire, UK
}

Change, the one true constant, is affecting IMIA as much as it is health systems around the world. As the leading global health informatics organisation, IMIA is pro-actively developing a vision, the IMIA Strategic Plan [1], for its future, its structure and functions, and its relationships with the wider world. A key part of building and sustaining the future of IMIA will be its network of Working Groups and Special Interest Groups (WG/SIG). IMIA's WG/SIG also have direct relevance and contribute to the theme and supporting sub-themes of Medinfo 2007, 'Building sustainable health systems'. Sustainability is described as

an attempt to provide the best outcomes for the human and natural environments both now and into the indefinite future. It relates to the continuity of economic, social, institutional and environmental aspects of human society, [and] is intended to be a means of configuring civilization and human activity so that society, its members and its economies are able to meet their needs and express their greatest potential in the present, while ... planning and acting for the ability to maintain these ideals in a very long term. [2]

To support IMIA's contribution to the best outcomes and to helping sustain viable and appropriate health systems in all parts of the world, its WG/SIG must determine appropriate areas on which to focus activities. IMIA's 20 Working Groups (WG) and one Spe- cial Interest Group (SIG) cover many aspects of the discipline of health informatics, but have not always developed in a planned way. They have often emerged as IMIA members, or the IMIA Board, have seen a need to address a particular aspect of the discipline. Our two newest groups, 'Smart Homes and Ambient Assisted Living' and 'Human Factors Engineering for Healthcare Informatics', reflect the need for IMIA to address important emerging or established aspects of health informatics.

As the technologies of healthcare evolve, it will be increasingly important for IMIA to foresee emerging areas where we need to be involved, or even influence future developments. We need to address not only current and emerging technological and biomedical aspects of health systems, but also the social, organisational and economic aspects. IMIA is therefore participating in a project in conjunction with the British Computer Society Health Informatics Forum and CHIRAD, an Academic Institutional member to build on the IMIA Scientific Content Map, and develop a cognitive mapping of the discipline of health informatics. The results will contribute to defining the Knowledge Core at the centre of IMIA's Strategic Plan, but will also provide an opportunity to map our existing WG/SIG against the elements of the discipline as they emerge from consensus discussions, as determined and validated by international health informatics experts.
If we are to address the challenges for health among and between developed and developing nations and regions, we need to exchange information and foster activity between different parts of the world. I wish to build on the good work that many IMIA WG/SIG already do in joint activities with groups in other informatics organisations, in particular, long-standing collaboration with WGs in EFMI (the European Federation for Medical Informatics) and AMIA (the American Medical Informatics Association).

While IMIA's active network of WG/SIG are lead by recognised experts in their fields, the time and energies they are able to devote are all carved from their 'spare' or volunteer time; I and my predecessors in the role of Vice President for Working Groups and Special Interest Groups are eternally grateful to all our WG and SIG leaders, past and present, for the amount of time and energy they do manage to devote. I am pleased to present you with their reports, and invite anyone interested in joining a WG/ SIG or who have views on where we may need to develop new groups to contact the group leaders or myself.

\section{References}

1. IMIA Strategic Planning Task Force. Strategy in a Fishbowl: An invitation to determine the shape of IMIA in 2015. Methods Inf Med 2006, 45:235-9.

2. Wikipedia [Online]. Sustainability. 2007 Jan 29 [cited 2007 Jan 29]. Available from: URL:http:// en.wikipedia.org/wiki/Sustainability 


\section{Nursing Informatics (Special Interest Group 1)}

\author{
Chair (2006-09): \\ Robyn Carr (NewZealand) \\ Director, Informatics Project Contracting (IPC) \& Associates \\ 27 Byron Street \\ Cambridge, Waikato, NewZealand 2351 \\ E-mail: rcari@nznet.gen.nz \\ Vice Chair, Working Groups (2006-09): \\ Heimar Marin (Brazil) - Working Groups (Chair Elect 2009) \\ Professor, Nursing Informatics Group \\ Federal University of Sao Paulo \\ Rua Napoleao de Barros 754 \\ Sao Paulo Brazil Cep: 04024.002 \\ E-mail:hfmarin@alttglobal.net

\section{Vice Chairs:} \\ Hyeoun-Ae Park (Korea) - Administration and Finance (2006-09) \\ E-mail:hapark@snu.ac.kr \\ Patricia Abbott(USA)-Membership (2006-09) \\ E-mail: pabbott2@son.jhmi.edu \\ Thomas Buerkle (Germany) - Communication (2006-09) \\ E-mail: thomas.buerkle@imi.med.uni-erlangen.de \\ Website: http://wmw.imia.org/ni/index.html
}

The IMIA Special Interest Group on Nursing Informatics (IMIA-NI) aims to promote nursing informatics research, education, development and application to support the health of people worldwide. This is undertaken through the work of its members, their local activities, working groups and through the world congress, which is held every three years.

The bylaws have been revised, creating a new look executive committee, with a chair and a four vice chairs with specific roles. This will help to ensure that the structure and processes adopted by IMIA-NI enable it to maximise the efforts of the nursing informatics community to meet its future aims and objectives including increasing our network and membership; supporting a more open and democratic executive committee; and ensuring we deliver our new strategy.

\section{Recent Activities:}

NI 2006 Congress: an excellent nursing informatics world congress met on June 11-14 2006 in Seoul, Korea with the theme of 'Consumer-Centered, ComputerSupported Care for Healthy People'. Dr Hyeoun-Ae Park, IMIA-NI Rep, for Korea chaired the Organising Committee. There were 354 Presentations, with 712 participants from 34 Countries. 10 Student awards were presented, from among 25 competitors (17 Papers and 8 Posters), while 193 Participants attended study tours to 6 medical sites. A Post Conference workshop was held with the theme 'Nursing Informatics 2020: Towards Defining Our Own Future'.

During NI2006, a Leaders Group meeting was held which included the working group chairs and IMIA-NI Officers. This group is a standing Advisory Group of IMIA-NI, to provide collaboration and integration across working group activities to enable the strategic direction and advice to IMIA NI. This group will be chaired by the Vice Chair Working Groups, Heimar Marin. There are currently 9 Working Groups - NI Management (NIM), NI Open Source, NI Consumer/Client Health Informatics, NI Nursing Concept Representation, NI Evidence Based Practice, NI Education, NI History and NI Standards. A new working group on 'Process Driven Implementation Strategies', will be chaired by Rosemary Kennedy. Members of the nursing informatics community have collaborated on a book, which was launched during NI2006, and which has proved very popular. Titled 'Nursing and Informatics for the $21^{\text {st }}$ Century - An international Look at Practice, Trends and the Future', the book is edited by Charlotte Weaver, Connie Delaney, Patrick Webber, and Robyn Carr. Many IMIA-NI members have written chapters. This publication has proved very popular, many request have been received, from all corners of the world, for a copy.

IMIA-NI national members undertake a wide range of activities that support nursing informatics in member countries. Reports in full are available on the Web Site.

\section{Future Activities:}

IMIA-NI is pleased to participate in the task force which has been created to explore IMIA's role with respect to biosurveillance. Kathleen McCormick, the chair of the IMIA-NI Standards Working Group, will be the group's representative on the task force.

Electronic communication is vital among our members as they are unable to meet regularly. We have been very extremely fortunate to have Steven Huesing $\bullet f$ s ongoing support with our web page. Thomas Beurkle will be working with Steven to provide procedural documentation to assist members and provide other updated materials. Preparations are underway for NI 2009, which will be held in Helsinki, Finland on June 28 - July 1, 2009 (http://www.ni2009.org/). 


\section{Objectives:}

To promote applications in medicine and biology focusing on methods of pattern recognition and interpretation. This WG is primarily oriented to methodology, but also addresses a variety of problems in clinical disciplines, environmental medicine, behavioural sciences and psychology. Observable phenomena recorded as signals, images and other meaningful patterns are regarded in respect to diagnoses, therapy planning, surgery and modelling. Four different steps are always involved in these complex procedures:

1. data acquisition of biosignals and medical images,

2. digital data processing for deriving significant features,

3. classification, and

4. interpretation.

\section{RecentActivities:}

The 5th International Workshop on Biosignal Interpretation was held in Tokyo, Japan 6 - 8th September, 2005. It was a joint initiative of the Japanese Society for Medical and Biological Engineering (JSMBE), IMIA, IFMBE and IEEE EMBS. It was financially supported by the Japanese Government and by Hosei University, the local hosting institution. Prof. Kazuo Jana, general chairman, provided an extremely ambitious scientific program which touched all current fields in signal as well as in image processing. The scientific program included the topics Heart Rate Variabilty, Brain Dynamics and Imaging, Emerging Health Care Technologies, Detection and Diagnostic Systems, and Neurodynamics. A special issue of the Journal Methods of Information in Medicine is in preparation pooling the most interesting contributions of this workshop. We look forward to meeting all interested colleagues in 2008 in the US for the 6th. Workshop which will be held in Boston or New York.

Several papers on biomedical pattern recognition were presented at MIE2006 in Maastricht in August 2006, although many WG members were also active participants and presenters in the Annual International Conference of the IEEE Engineering in Medicine and Biology Society, EMBC06, in New York.

\section{Objectives:}

- The Working Group focuses on a broad scope of statistical methods in medicine and health care, including their contribution to a broad field of biomedical applications, e.g. clinics, epidemiology, genetics, pharmacology, and other areas of healthcare, including clinical trials, meta-analysis, data mining, and decision support.

- Critical analysis of papers in biomedical journals requires an understanding principles of statistics to guarantee both the scientific quality and practical significance of published results.

- Statistical methodology plays a great role in many aspects of information processing, contributing to both biomedical research and healthcare applications. It is concerned with different aspects of data collecting (sampling methods) and data processing (computational statistics), using statistical tools for estimation of unknown population parameters and hypotheses testing.

\section{Biomedical Pattern Recognition}

\author{
Chair (2004-2007): \\ Dr. Hartmut Dickhaus \\ Institute for Medical Biometry and Informatics \\ Department of Medical Informatics \\ University of Heidelberg, Im Neuenheimer Feld 400 \\ D-69120 Heidelberg, Germany \\ Tel.: + $496221567483 / 2$ \\ Fax: +496221564997 \\ E-mail:hartmut.dickhaus@med.uni-heidelberg.de \\ Website: http:// www.med.uni-heidelberg.de/mi
}

\section{Biomedical Statistics and Information Processing}

\author{
Chair(2004-2007): \\ Prof. Dr. Jana Zvárová \\ European Centre for Medical Informatics, Statistics, and \\ Epidemiology \\ Charles University and Academy of Sciences \\ Pod Vodárenskou Vezi 2, 18708 Prague \\ The Czech Republic \\ Tel: + 420-2-66053097 \\ Fax: + 420-2-86581453 \\ E-mail: zvarova@euromise.cz.
}


Information on IMIA

\author{
Co-Chair (2004-2007): \\ Prof. Leon Bobrowski \\ Insitute of Biocybernetics and Biomedical Engineering \\ Polish Academy of Sciences \\ Trojidena 3, Warsaw, Poland \\ Tel: + 48-22-6599143 ext. 416 \\ Fax: +48-22-6597030 \\ E-mail: Leon.Bobrowski@ibib.wow.pl
}

\section{Consumer Health Informatics}

\section{Chair (2006-2008):}

Gunther Eysenbach, MD

University of Toronto; Toronto General Hospital

R. Fraser Elliott Building, 4th Floor,

Room \# 4S435,

190 Elizabeth Street

Toronto, ON M5G2C4

Tel: +14163404800 Ext. 6427

Fax: +14163403595

\section{Recent Activities:}

- WG members have been active in conferences and workshops connected with statistics in biomedicine and healthcare, especially during the MIE conferences (Geneva 2005 and Maastricht 2006), the conference in Bialystok (February 2005) and workshop in Prague (December 2005). Selected full papers of the IMIA working conference organized by the Working Group titled 'Statistical Methodology in Bioinformatics and Clinical Trials', held in Prague, 2004, were reviewed and published in the special issue of the Methods of Information in Medicine in 2006.

- The WG seeks to establish closer contacts with the International Society for Clinical Biostatistics and several members participated at the ISCB conferences in Szeged 2005 and Geneva 2006.

\section{Scope:}

The CHIWG is concerned with the evaluation of electronic information related to health care available to the public (e.g. Internet, wireless, standalone electronic media), the quality of information, education of the public, ethical issues related to the electronic information, and the effect on a person's health care and relationship with health care providers.

\section{Group Activities:}

The main activity of the WG was to organize the MEDNET eHealth conference (www.ehealthcongress.org) in Toronto, Oct 14-19, 2006, which was chaired by Gunther Eysenbach, and - for the first time - was positioned and branded as an IMIA WG CHI event.

The theme of the conference was 'Improving Public Health through the Internet', and it was co-sponsored by major agencies and organizations such as the National Cancer Institute (US and Canadian) and the Canadian Institutes for Health Research (CIHR). It was a significant success with about 500 participants and over 350 presentations covering CHI-relevant topics. The complete final abstract book can be downloaded at http://yi.com/mednet06/draft-mednet2006book.pdf.

\section{Objectives for the next 3 years:}

The WG looks forward to greater participation in key IMIA activities, increasing the visibility and impact of CHI WGs in the world by:

- providing greater opportunities to share CHI related information from sources such as the International Journal of Medical Informatics (IJMIA), and the Journal of Medical Internet Research (JMIR). Emphasis will be given to highquality studies and randomized trials published in quality journals.

- holding a business meeting at Medinfo 2007.

- continuing to liaise with counterparts in other countries, such as the AMIA WG CHI, EFMI, IMIA's NI-SIG (WG on CHI).

- expanding our contacts with $\mathrm{CHI}$ interest groups in Asia and Africa. 


\section{Objectives:}

To bring the small, but rapidly growing, community of dental informaticians around the world into closer contact.

\section{RecentActivities:}

- More members have joined this working group; there are currently 92 list members and 60 web members.

- The Dental Informatics working group home page (http://www.ecs.gannon.edu/ IMIA) has been updated, including member pages.

- Worked with the AMIA Dental Informatics group on the "Dental Informatics Online Community" project to receive a grant from National Library of Medicine.

\section{Future Activities:}

- We aim to focus on improving access to information of dental informatics through the WG website.

\section{Objectives:}

- To disseminate and exchange information on Health and Medical Informatics (HMI) programs and courses and promote the IMIA HMI database on HMI education.

- To produce international recommendations on HMI programmes and courses.

- To support HMI courses and exchange of students and teachers.

- To advance the knowledge of: (1) how informatics is taught in the education of health care professionals around the world, (2) how in particular health and medical informatics is taught to students of computer science/informatics, and (3) how it is taught within dedicated curricula in health and medical informatics.

\section{Recent Adtivities:}

- The recommendations of the IMIA on Education in Health and Medical Informatics have been translated into Spanish, Chinese, Italian, Turkish, Czech and Japanese.

- Publication of the book 'Globalization of Health Informatics Education', IOS Press, Volume 109, Studies in Health Technology and Informatics, Edited by: E.J.S. Hovenga and J. Mantas 2004, (ISBN: 158603454 5)

- The conference "Health and Medical Informatics Applications - Educational Aspects" took place in Athens, Greece in 19-20 March 2005, and was supported by the IMIA Education WG and EFMI WG EDU. A special issue of 'Methods on Information in Medicine' is to publish a selection of papers.

- A meeting during MIE2005 in Geneva, Switzerland discussed issues related to the $\mathrm{WG}$ and the academic members.

\section{Future Activities:}

- Revision of IMIA Recommendations on HMI Education by forming a Task Force and running a series of meetings/workshops.

- Promote international dialogue concerning the training of health/biomedical informatics professionals. Identify opportunities for collaboration in such training.

- Organise a working group workshop/conference.

\section{Dental Informatics}

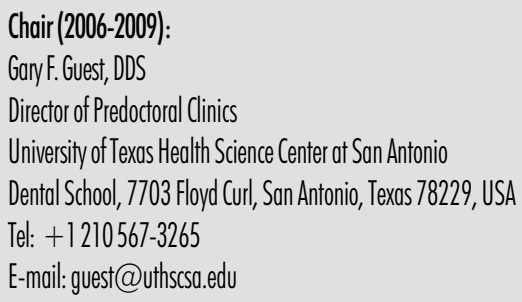

Website: http://www.ecs.gannon.edu//MIA

\section{Health and Medical Informatics Education}

\author{
Chair (2006-2009): \\ Professor William Hersh, MD \\ Department of Medical Informatics and Clinical Epidemiology \\ Oregon Health and Science University \\ 3181 SW Sam Jackson Park Road \\ Portland, Oregon, 97239, USA \\ Tel: + 1-503494-4502 \\ Fax: + 1-503494-4551 \\ E-mail:hersh@ohsu.edu \\ Co-chair (2006-2009): \\ Professor John Mantas, PhD \\ Health Informatics Laboratory \\ Faculty of Nursing \\ University of Athens \\ 123 Papadiamantopoulou Street \\ GR-11527 Athens, Greece \\ Tel: $+30-210-7461459 / 60$ \\ Fax: +30-210-7461461 \\ E-mail:.jmantas@cc.uoa.gr \\ Website: http://www.imia.org/wgl
}




\section{Health Informatics for Development}

\author{
Co-Chair(2004-2007): \\ Dr. Jean Roberts \\ Phoenix Associates, 68 Churnet Valley Road \\ Kingsley Holt, ST102BQ \\ United Kingdom \\ Tel/fax: + 441538753297 \\ E-mail: jean@hcjean.demon.co.uk \\ Co-Chair (2004-2007): \\ Prof. Dr. George I Mihalas \\ "Victor Babes" University of Medicine and Pharmacy \\ Effimie Murgu Sq. 2, zip 300041 \\ Timisoara, Romania \\ Telffax: +40-256-490288, mobile: +40-722-734690 \\ E-mail:mihalas@umft.ro \\ www.medinfo.umft.ro
}

\section{Health Information Systems}

Chair (2006-2009):
Christian Lovis
Swiss National Foundation Professorship
School of Medicine
UniversityofGeneva
Switzerland
Tel.: + 41 22372-6201
Fax: +41 22372-8680
E-mail: christian.lovis@hcuge.ch
Cc-chair(2006-2009):
Dr. DominikAronsky, MD, PhD
Vanderbilt UniversityMedical Center
Nashville TN
Tel: + 16159361068
E-mail: Dominik.aronsky@vanderbilt.edu

\section{Objectives:}

- To explore how health care informatics could improve living conditions in developing regions and implement programs in that direction.

- Organization of forums for exchange of experiences of colleagues working in the field of health informatics.

- Making a list of the needs and resources in medical informatics for each country.

- Organization of educational activities in developing regions, especially through the implementation of professors $\bullet$ exchange.

- Organizing workshops and seminars with international experts participation

\section{Recent and Future Activities:}

Our WG has not been collectively very active despite significant activity in some individual countries. It is our intention to rectify this in 2006/2007 with the production of a book with the working title of 'Informatics Perspectives - Issues and Similarities for Developing and Developed Countries' in conjunction with the EFMI region. The aim of the book is to take key issues of current interest, produce a discussion paper on them and publish the narrative on each topic with accompanying reflections from both a developed and developing perspective.

We invite other IMIA regions and interested parties, whether from developed or countries in transition to comment on the topics suggested, give contact details of potential authors and commentators for the topics outlined, and suggest contacts for any other topics they feel important.

\section{Objectives:}

- To provide a forum for collaboration among members and to promote systematic development and research in the field of health information systems.

- To identify and assess problems and success factors of health information systems and to provide intensive feedback between the scientific community, healthcare professionals, and the health IT industry. This implies a 'horizontal' orientation with close contact to other working groups.

\section{Recent Activities:}

The WG held a successful conference from July 2-4, 2006, in Oeiras, near Lisbon, Portugal in cooperation with the IMIA WG Telematics in Healthcare. It was hosted by INA, the Portuguese Instituto Nacional de Administraõ, an institutional member of IMIA, with the theme of 'Expanding the Scope of Health Information Systems from Hospitals to Regional Networks, to National Infrastructures, and Beyond'.

The conference focussed on concepts to improve health care by exchanging, sharing, and reusing data between health care institutions on all levels of care. Central challenges addressed were interoperability, ubiquitous access, common data models and terminologies, political mandates and lack of continuity, as well as related socio-technical aspects. International speakers presented experiences and concepts, which were further discussed in working groups. A special issue of Methods of Information in Medicine will appear to distribute the results of the presentations and of the discussion groups.

\section{Future Activities:}

A follow-up conference at Vanderbilt University, USA in 2007 is proposed. 
Objectives:

- To promote methods and techniques devoted to the study of human factors in the field of Biomedical Informatics.

- To coordinate studies and actions in this domain and to develop standardization initiatives for usability studies and user-centered design in the healthcare domain, confronting state of the art methods, models, innovations and results.

- To disseminate rigorous scientific principles for performing formal usability evaluations to improve their degree of efficiency, acceptability and safety of health informatics applications.

\section{Focus:}

Human factors can be the difference between systems that function well in the clinical environment and systems that function poorly. Human factors engineering is the field of study which deals with the cognitive aspects of the human computer interaction. This working group will explore methods for studying the computer-human interaction in health, including regarding optimal interface designs for health informatics software to make the computer a welcome partner with both the clinician and the patient in the empowered longitudinal care of the individual.

\section{Recent Activities:}

A first successful workshop took place in May 2006 in Lille (France), to start the international network in this HF engineering domain. There were 40 attendees from Europe and the United States, and the following day a symposium was held where there were 120 participants. This workshop took the form of basic training and tutorials on usability studies in the Evalab environment, and also explored recent studies on HF related problems in Biomedical Informatics and initiated reflection on usability methods and their adaptation to the specific domain of Biomedical Informatics. A second symposium with 60 participants was held in Rochester, MN, USA on August 23-25th. Discussions centered on the role of human factors and Usability studies on the certification of intelligent electronic health records.

\section{Future Plans:}

We will develop a web site with a semantic wiki for furthering discussions, liaise with other IMIA, EFMI and AMIA working groups in the area of human factors and evaluation. We plan meetings, including an annual symposium, with the next one in Denmark in 2007. We will work on developing sets of standards for the human factors studies needed to certify electronic health records and will develop a research agenda for human factors in health informatics, which will lead to a white paper.

\section{Human Factors Engineering for Healthcare Informatics}

\author{
Chair (2006-2009): \\ Dr Peter L. Elkin, MD, FACP \\ Professor of Medicine \\ Mayo Clinic College of Medicine \\ Rochester, MN, USA \\ Tel: + 15072841551 \\ Fax:+15072845370 \\ E-mail:Elkin.Peter@mayo.edu \\ Co-chair (2006-2009): \\ Prof. Marie-Catherine Beuscart-Zéphir, PhD \\ Lab Manager, EVALAB \\ Lille University Hospital \& School of Medicine \\ Lille, France \\ Tel: +1133320623461 \\ Fax: + 1133320521022 \\ E-mail: mcbeuscar!@univ-lille2.fr
}




\section{Informatics in Genomic Medicine (IGM)}

\author{
Chair (2004-2007): \\ Dr. Fernando J. Martin-Sanchez, PhD \\ Head of the Medical Bioinformatics Department \\ National Institute of Health 'Carlos III' \\ Majadahonda, Madrid \\ Spain \\ Tel: +34918223219 \\ Fax: +3491 8223259 \\ E-mail:fms@isciii.es

\section{Co-Chair (2004-2007):} \\ Peter Tarcy-Hornoch, M.D. \\ Head, Division of Biomedical and Health Informatics \\ University of Washington, Seattle WA \\ USA \\ Tel: +12066858093 \\ Fax: +12065433461 \\ E-mail: pth@u.washington.edu
}

\section{Objectives:}

Opportunities arise within the discipline of biomedical informatics to facilitate the advancement of genomic and individualised medicine. To effectively link the genotype and phenotype a bi-directional flow of data, tools and methods between two traditionally separate areas of informatics (clinical informatics and bioinformatics) must be ensured. These interests include, but are not limited to:

- Integrating molecular and genomic information into health information systems and tools.

- Generating structured, standardised, anonymous clinical data sets (phenomic data) to be used in the context of post-genomic research.

- Facilitating new approaches for the integration and analysis of different levels of information about diseases (grid, biobanks, disease modelling and simulation, mapping of clinical and genetic databases and ontologies).

The IGM WG aims to:

- Provide a forum to enhance collaboration, share experiences, and promote research in this field

- Increase communication with other working groups and organizations, including groups with an emphasis on genomic medicine and informatics.

- Establish itself as a scientific reference on issues related to information technology projects in genomic medicine.

\section{Recent Activities include:}

- Contacts with ERCIM's (European Research Consortium for Informatics and Mathematics) Working Group in Biomedical Informatics.

- Presentation at the European Commission "e-Health High level Conference and Exhibition' Malaga, Spain. May 2006.

- Guest edition of the Special Issue 'Biomedical Informatics: Research and Applications' for the IEEE Transactions on Information Technology in Biomedicine. In preparation.

- Membership of the Program Committee for the Track 'Bioinformatics and its Medical Applications', 19th IEEE International Symposium on Computer-Based Medical Systems (IEEE CBMS 2006), Salt Lake City, USA. June 2006.

- Participation in research projects funded by the European Commission (Information Society Technologies Program), including SYMBIOMATICS (European Research Area Network. Specific Support Action: Synergies in Medical Informatics and Bioinformatics) and BEYOND THE HORIZON (Coordinated action, supported by the Information Society Technologies/Future and Emerging Technologies programme (IST-FET) of the European Commission).

\section{Future Activities:}

- Publication of the Web page and setting up collaborative information services and tools (Wiki, mailing list, forum)

- To consolidate a community of scientists interested in the application of Informatics to facilitate individualised healthcare and to start conversations with other relevant stakeholders in Biomedical Informatics (ISCB, HL7), including the AMIA GEN-WG (Genomics).

- To explore the field of Health Applications of Convergent Tecnologies (NBIC) and possible links to IMIA. 


\section{Objectives:}

- To increase awareness and acceptance of intelligent data analysis and data mining methods in the medical community.

- To foster scientific discussion and disseminate new knowledge on AI-based methods for data analysis and data mining techniques applied to medicine.

- To promote the development of standardized platforms and solutions.

- To provide a forum for presentation of successful intelligent data analysis and data mining implementations in medicine, and for discussion of best practices in introduction of these techniques in medical and health-care information and decision support systems.

\section{Recent Activities:}

- The WG organized the 11th workshop on Intelligent Data Analysis in Medicine and Pharmacology, held in Verona, Italy on August $25-26^{\text {th }} 2006$, with the main topic being 'Temporal data mining'. We had 40 participants from Europe, United States and Australia, with 16 papers, a panel and two invited talks.

- A Special Issue of Artificial Intelligence in Medicine on IDA in Medicine has been published (Artif Intell Med. 2006 Jul;37(3)), edited by Blaz Zupan, John Holmes and Riccardo Bellazzi. It contains contributions that deal with methods for gathering new knowledge using a selected data analysis approach, all of which were first presented at the $9^{\text {th }}$ IDAMAP, an International Workshop on Intelligent Data Analysis in Medicine and Pharmacology, at Stanford University in 2004.

- Selected papers presented at IDAMAP 2005 have been invited for submission to a Special Issue of the Journal of Biomedical Informatics.

\section{Future Activities:}

- IDAMAP 2007 will be held in Amsterdam, on July $7^{\text {th }} 2007$, on the occasion of the AI in Medicine (AIME) conference.

- During the IDAMAP 2007 meeting there will be a voting for the new chairman and co-chairman for the WG, to take office from 2008.

- The working group will focus in particular on exploring the following issues: 1. the exploitation of predictive data mining in clinical medicine,

2. knowledge-based functional genomics,

3. IDA of molecular phenotypes,

4. data mining models for the assessment of clinical risk,

5. temporal data mining in medicine and bioinformatics.

\section{Intelligent Data Analysis and Data Mining}

\author{
Chair (2006-2008): \\ Prof. Dr. Riccardo Bellazzi \\ Dipartimento di Informatica e Sistemistica \\ Universit? di Pavia \\ via Ferrata 1,27100 \\ Pavia, Italy \\ Tel: + 39-0382-985511 \\ Fax: +39-0382-985373 \\ E-mail: Riccardo.Bellazzi@unipv.it \\ Co-chair (2006-2008): \\ Prof. Dr. Blaz Zupan \\ Faculty of Computer and Information Sciences \\ University of Liubliana \\ Trzaska 25, 1000 \\ Liubliana, \\ Slovenia \\ and \\ Department of Human and Molecular Genetics \\ Baylor College of Medicine \\ Houston, Texas \\ USA \\ Tel: + 386-1-4768-402 \\ Fax: +386-1-4264-647 \\ E-mail: blaz.zupan@fri.uni-li.si
}




\section{Medical Concept Representation}

\author{
Chair (2004-2007): \\ Dr. Christopher G. Chute \\ Professor and Chair, Biomedical Informatics \\ Department of Health Sciences Research \\ Mayo Foundation, Rochester, MN55905 \\ USA \\ Tel: + 1-507-284-5541 \\ Fax: + 1-507-284-0360 \\ E-mail:chute@mayo.edu \\ Website: http://www.imia.org/wg6
}

\section{Mental Health Informatics}

\author{
Chair (2006-2009): \\ Naakesh A. Dewan, M.D. \\ President \\ American Association for Technology in Psychiatry \\ Advanced Psychiatry, P.A. \\ Center for Mental Healthcare Improvement \\ 2519 N. McMullen Booth Road, Suite 510-255 \\ Cleanwater, FL33761 \\ Tel: $+1727723-0779$ \\ Fax: + 1727 723-0770 \\ E-mail:drdewan@advancedpsychiatry.com
}

\section{Objectives:}

To provide a forum for state of the art dialogue and collaboration on natural language processing and concept representation in healthcare applications, IMIA's Medical Concept Representation Working Group is the international forum for issues related to informatics in the classification and coding of health data. The working group is charged with:

1) Reviewing health data nomenclature and classification needs for the world community;

2) Evaluating information processing technology in meeting these defined needs; and

3) Recommending methods for future classification and nomenclature systems.

\section{Recent Activities:}

- Joint panels on Terminology and Natural Language Processing were conducted at Medinfo 2004 with MIE and AMIA working groups.

- A resumption of the triennial meeting series took place in Rome, Italy from April 29-May 2, 2005. Dr. Barry Smith of the University of Buffalo and The Institute for Formal Ontology and Medical Information Science, part of the Faculty of Medicine of the University of Leipzig, was Program Chair. Proceedings appeared in the Journal of Biomedical Informatics as a special issue of the Journal of Biomedical computing in June, 2006.

\section{Future Activities:}

- WG6 will convene at MedInfo 2007 in Brisbane to plan a WG symposium in 2008.

\section{Background:}

The MHWG of IMIA has been in existence since 2000, and during this time, the world of informatics in mental health has exponentially changed. Now consumers can use the web for actual therapy, clinicians can peek into functioning of the brain during cognitive tasks, and patients can be seen by their clinicians via telepsychiatry. Yet, we have not developed ways that informatics can reduce the disease burden of psychiatric disorders, increase collaboration between medical and mental health clinicians, or shared best practices in research, practice, or policy. If an international body can make a difference, it should be in transforming the burden of mental health disorders worldwide and being an international best practices exchange group. There exists today a critical mass of informatics innovators who function as researchers, developers, and policy leaders who have no forum to share perspectives and shape the future of mental health informatics.

I propose four goals to be achieved by 2009:

- Formal collaboration with the WHO mental health initiative

- An Annual Publication of International Best Practices in research, policy and practice in collaboration with Elsevier

- An Informatics Policy Framework that would allow medical and mental health clinicians to share information to the betterment of patients and society while protecting confidentiality and privacy.

- Corporate, Foundation, and Governmental Support to fund the functions of the IMIA Workgroup 


\section{Objectives:}

The focus of the WG remains on educational, promotional and 'evangelistic' activities to raise awareness of free/libre software and open source software, including GNU/Linux.

The objectives are:

- to provide a forum for discussion of the application of free/libre and open source solutions within health, healthcare and health informatics.

- to bring together experts and interested individuals to explore the potential application of free/libre and open source solutions within their domains of expertise and for all aspects of IMIA's areas of interest.

- to work with other IMIA Working and Special Interest Groups to explore the appropriate use of free/libre and open source solutions and applications.

- to facilitate both the use of other groups' expertise in the areas under consideration, and the input of IMIA views to those other groups' work and discussions.

\section{RecentActivities:}

- Presentations at the V International Congress of Informatics in Health and the II Intercambio Informatica en Enfermeria (Second Interchange on Nursing Informatics) held at CECAM (Centro de Cibernetica Aplicada a la Medicina) in Havana, Cuba in May 2005.

- Peter Murray gave a keynote presentation at the Libre Software Meeting (Medicine track), July 5-9, 2005, at Dijon, France.

- At SINI2005 (Summer Institute in Nursing Informatics of the University of Maryland School of Nursing, July 20-23) in Baltimore, USA, a panel session on open source and free software was supported by the IMIA OSWG and IMIA-NI OSNI WG.

- MIE 2005, a workshop 'Exploring a European dimension to free/libre and open source software (FLOSS) in health and nursing informatics';

\section{Future Activities:}

- The WG is collaborating with the EFMI WG and CHIRAD to co-ordinate the EFMI special topic conference on open source in London in 2008.

- A meeting in conjunction with the BCS HIF in April 2007 in London.

- The WG will be hosting two meetings at medinfo2007.

\section{Objectives:}

- To investigate and evaluate organizational, social, ethical, and individual behavioral issues surrounding the introduction and use of informatics applications.

- To determine strategies for product design and technological change to support health care delivery through information and communication technologies.

- To incorporate organizational change management and human concerns into information technology projects.

\section{RecentActivities:}

- Co-sponsored with the AMIA People and Organizational Issues WG a Doctoral Consortium to precede the AMIA 2005 and 2006 Symposia.

- Organized a panel on ubiquitous computing in health care for the IFIP WG 8.2 conference on "Designing Ubiquitous Information Environments: Socio-technical Issues and Challenges," Cleveland, OH 2005

\section{Open Source Health Informatics}

\author{
Chair (2005-2008): \\ Prof. Graham Wright \\ CHIRAD (Centre for Health Informatics Research and Development) \\ 41 Firs Road, Firsdown Salisbury SP5 ISJ \\ United Kingdom \\ Tel: +44(0) 1980863953 \\ E-mail: profwright@gmail.com \\ Co-Chair (2004-2007): \\ MUDr. ing. Jan Vejvalka, Dept. of Applied Informatics \\ 2nd Medical Faculty, Charles University \\ Vuvalu 84, 15006, Praha 5 \\ Cech Republic \\ Tel: +420257210345 , ext. 272 \\ Fax: +420224435820 \\ E-mail:jan.vejvalka@lfmotol.cuni.cz \\ Website: www.chirad.info/imiaoswg/
}

\section{Organizational and Social Issues}
Chair (2004-2007):
Dr. Bonnie Kaplan
Yale Center for Medical Informatics
Yale University
School of Medicine
33 Ingram Street
Hamden, $(T 06517$
USA
Tel: + 1203-288-5799
Fax: + 1-203-288-5799
E-mail: bonnie.kaplan@yale.edu 
Information on IMIA

\author{
Co-chair (2006-2009): \\ Madhu C. Reddy, PhD \\ College of Information Sciences and Technology \\ The Pennsylvania State University \\ University Park, PA 16802-6823 \\ USA \\ Phone:814-863-6316 \\ Fax: 814-865-6426 \\ E-mail:mreddy@ist.psu.edu
}

\section{Primary Health Care Informatics}

Chair (2006-2009):

Sheila Teasdale

PRIMIS + Strategic Director

15th Floor Tower Building

University of Nottingham, University Park

Nottingham NG7 2RD

UK

website: www.primis.nhs.uk

Tel: +441158466420

E-mail:sheila.easdale@primis.nottingham.ac.uk

Co-chair(2004-2007):

Professor Michael Kidd, M.D.

Head, Department of General Practice

The University of Sydney 37 A Booth Street, Balmain 2041 Sydney Australia

Tel: + 61 (02) 9818 1400;

Fax: +61 (02)98181343

E-mail:michael.kidd@gp.med.usyd.edu.au
- Organized a workshop on "Avoiding The F-Word: IT Project Morbidity, Mortality, and Immortality," co-sponsored by nine AMIA WGs, for AMIA 2006 Symposium

- Participated in keynote panel on "evaluation" at AMIA Spring 2006 Congress.

\section{Future and Ongoing Activities:}

1. Nominate papers for the Diana Forsythe Award of the AMIA People and Organizational Issues WG, and serve on the Awards Committee.

2. Organize panels and tutorials at AMIA Symposia and Medinfo.

3. Develop curricula recommendations

4. Co-sponsor Information Technology in Health Care tri-ennial conferences

5. Co-sponsor AMIA People \& Organizational Issues WG Doctoral Symposium

\section{Objectives:}

To promote primary care informatics by:

- acting as a forum for exchange of ideas between its members

- providing information to its members to assist them in progressing primary care informatics in their own country

- increasing the understanding of primary care informatics issues with a view to publishing the results of these discussions.

\section{Recent Activities:}

- The journal, Informatics in Primary Care, was relaunched, with endorsement from IMIA WG5 and involvement of WG members on the Editorial Board. Full text is available to personal and library subscribers at: www.radcliffeoxford.com/ipc, and is now free full-text for papers over a year old.

- Members of the WG liaise at an international level on key local and regional initiatives in primary care informatics. Our key international partners include EFMI Working Group 7 (Primary Care), Informatics Working Party of WONCA (The World Organization of Family Doctors), and the AMIA Primary Care Informatics Working Group.

- The WONCA Informatics Working Party held a 2-day workshop in Prato, Italy, in August 2006; delegates participated to start the preparation of 6 position papers for publication in a special issue of Informatics in Primary Care, on Security, Clinical Decision Support, Information Sharing, Meeting Patient Needs, Education and Support for Family Doctors and Staff, and Quality and Secondary Uses of Data.

\section{Future Activities:}

- Preparation for Primary Care Informatics Day at Medinfo 2007.

- Continued development of recruitment plan for working group.

- Continued collaboration with Informatics in Primary Care journal.

- Enhanced website presence through the IMIA web site. 


\section{Objectives:}

To examine the issues of data protection and security within the healthcare environment. The Security in Health Information Systems Working Group addresses state-of-the-art security of distributed electronic patient records (EPR).

\section{RecentActivities:}

The working group conducted a working conference in Dijon France, April 27 30, 2006. The main theme of the conference was 'Secure eHealth: managing risk of patients data', with four sub-themes, ie Telecommunication and Wireless Technologies; Ethics and Laws for eHealth in Telemedicine; Long Term Data Preservation and Intelligibility; and Security of Community Wide Health Care Records. The conference was attended by 43 participants from 14 countries, including representatives of private industry, governmental organizations and academia. Sixteen of the presented papers were selected for publication in an upcoming Special Issue of the International Journal of Medical Informatics, which is expected to be published early in 2007. The conference coincided with the 30th anniversary of the working group. The Gerd Griesser Award for the best paper contributed by a student or young investigator to one of the working group's working conferences (and which carries a value of 1,000 Euro ) was awarded to Dr. Moritz Y. Becker (member of the Security Group at Microsoft Research in Cambridge, UK), for the paper 'Information Governance in NHS's NPfIT: A Case for Policy Specification'.

The Working Group adopted a regular mode of leadership transition with the election of a Vice-Chair every three years, who is to succeed the current Chair. Francois Allaert, France, and Kiyomu Ishikawa, Japan, were elected as Chair and Vice- chair respectively to succeed Jochen Moehr, Canada.

\section{Goals and Objectives:}

The aim of this (new) working group is the study and promotion of research and development in the area of smart homes and ambient assisted living applications. A 'smart home' is a residential setting equipped with a set of advanced electronics, sensors and automated devices specifically designed for care delivery, remote monitoring, early detection of problems or emergency cases and promotion of residential safety and quality of life. Information and Communication Technologies (ICTs) are utilized to allow individuals to live independently in their preferred environment. Thus, systems are patient-centered rather than institution-centered as they are designed to address the needs of individuals, their families and caregivers rather than these of health care facilities. Furthermore, such technologies can allow for the detection of emergencies and provide the means to increase social interaction and minimize isolation for residents (by increasing access to information, entertainment resources and communication with peers).

The Working Group provides a forum for ongoing discussion and a collaborative platform for research and development combining expertise in engineering, sensor technologies, ubiquitous computing, health systems, gerontology and human computer interaction. We will address not only technical challenges but also the end users' needs, ethical, clinical and policy issues and the design of sustainable and non-obtrusive interventions, providing a holistic examination of the current status and future trends in smart homes and ambient assisted living.

\section{Security in Health Information Systems}

\author{
Chair(2006-2009): \\ Prof. dr. Francois André Allaert \\ Université de Bourgogne, (EN Biotech, CHRU du Bocage \\ F-21000 Dijon, France \\ Tel: +33380293431 \\ Fax: +33380293973 \\ E-mail:apsis@cenbiotech.com \\ Co-Chair (2006-2009): \\ Prof. Dr. Kiyomu Ishikawa \\ Department of Medical Informatics \\ Hiroshima University Medical Hospital \\ 1-2-3, Kasumi, Mianami-ku, Hiroshima, Japan \\ Tel: + 81-82-257-5080 \\ Fax.:+81-82-257-5084 \\ E-mail:kiyomu@hisoshima-u.ac.jp \\ EFMI Representative: \\ PD Dr. Bernd Blobel \\ Klinikum der Universität Regensburg, eHealth Competence Center \\ Franz-Josef-Strauß-Allee 11 \\ 93053 Regensburg, Germany \\ Tel: + 49941 944-6769 \\ Fox: +49941/944-6766 \\ E-Mail:bernd.blobel@klinik.uni-regensburg.de
}

\section{Smart Homes and Ambient Assisted Living}

Chair (2006-2009):
Dr. George Demiris, PhD
Associate Professor
School of Medicine \& Biobehavioral Nursing and Health Systems
University ofWashington, Seattle, WA, USA
E-mail: gdemiris@ @u.washington.edu
Co-Chair (2006-2009):
Guy Dewsbury
Research Associate
User-Centred Design of Assistive Technology Systems
Computing Department
Lancaster University, UK
E-mail: g.dewsbury@lancaster.ac.uk
Website: hittp://www.health-smarthomes.org/




\section{Standards in Health Care Informatics}

\author{
Chair (2005-2007): \\ Michio Kimura, M.D., Ph.D. \\ Vice President of Japan Association of Medical Informatics \\ Professor and Director of Medical Informatics Department \\ Hamamatsu University, School of Medicine \\ 1-20-1 Handa, Hamamatsu, 431-3192 \\ Japan \\ Tel: +81-53-435-2770 \\ Fax: +81-53-435-2769 \\ E-mail:kimura@mi.hama-med.ac.jp
}

\section{Technology Assessment \& Quality Development in Health Informatics}

\author{
Chair (2005-2008): \\ Dr. Jan Talmon \\ Dept. Medical Informatics, Maastricht University \\ PO Box 616, 6200 MD Maastricht \\ The Netherlands \\ Tel: +31433882243 \\ Fax:+31 433884170 \\ E-mail:talmon@mi.unimaas.nl
}

\section{Objectives:}

- To advise about standards from an academic perspective.

- To promote the mutual identification of needed standards world-wide.

- To share information to facilitate mutual coordination of standards development in health informatics.

The WG itself does not create new standards, rather, it devotes its activity in an advisory role to the promotion of mutual identification and coordination by posting and maintaining an inventory of health informatics standard activities. Usually, standard development activities are by volunteers, vendors, and immediate users and IMIA, as an academically oriented, world-wide organization, has connections to bring together countries which may currently participate less in existing standard development activities.

\section{Recent Activities:}

Post and maintain an inventory of health informatics standard activities. A web site (http://www.mi.hama-med.ac.jp/standardization.html), which links to current contents in http://www.med.kyushu-u.ac.jp/info/std/ reports up to date activities of ISO and CEN. This contains slides and handouts of the WG activities.

- A workshop was held at MIE 2005, with presenters including Gunnar Klein for CEN and ITU activites, Cor Loef for DICOM and IHE activities, Ken Toyoda for ISO TC 215 activities, and Yunkap Kwankam for WHO activities.

- A workshop, co-organized with APAMI WG1, was held at APAMI 2006 at Taipei, which focused on Global Vocabulary versus Local Healthcare Cultures. It is co-organized with APAMI WG1 (chaired by Prof. Kwak)

\section{Future Activities:}

- Provide advice from academic persepctives to activities and ISO/TC215 and CEN TC 251. (IMIA is already a liaison of ISO/TC 215.)

- Supply advice to activities for them to be world-wide, with the initial mission to highlight differences of health and personal information handling caused by each country's health and medical cultural differences.

\section{Recent Activities:}

Members of the Working Group have participated in various conferences, including:

- the AMIA Spring meeting, where a significant part of the program was devoted to evaluation;

- the Human Factors Engineering working conference in Lille. Discussions have taken place how to align activities with those of the new Human Factors Engineering WG.

Significant progress has been made with respect to the development of a statement on reporting of evaluation studies in health informatics (STARE-HI) and the development of guidelines for good evaluation practice in health informatics (GEP-HI). A draft version of STARE-HI was discussed during the MIE2006 conference in Maastricht. A first version of GEP-HI is being circulated for comments. These activities were undertaken largely in collaboration with the EFMI Working Group on Evaluation. 
Three publications from the chairs of the working group which are of larger relevance:

- Brender J: Handbook of evaluation methods. Academic Press, ISBN: 0123704642, 2005

- Brender J, Ammenwerth E, Nykanen P, Talmon J. Factors influencing success and failure of health informatics systems-a pilot Delphi study. Methods Inf Med. 2006;45(1):125-36.

- Talmon, JL: Evaluation and Implementation: A call for Action. In: Haux, R, Kulikowski, C, ed: IMIA Yearbook of Medical Informatics 2006. Methods Inf Med. 2006, 45 Suppl 1: S11-15.

\section{Future Activities:}

- Further development of STARE-HI and GEP-HI. Multi-journal publication of STARE-HI

- Development of accompanying papers with supportive evidence for STARE-HI.

\section{Objectives:}

- To explore the rationale and perspective of Health Telematics

- To promote the design and development of open architecture and inter-operability tools

- To promote the analysis, design and development of methodologies and applications to support collaborative work in healthcare information systems

- To share experiences on E-health, Telemedicine and Professional Healthcare networks.

\section{Recent Activities:}

Activities in 2006 were devoted to finding new directions in the study of the development of Telemedicine and Communicating Medicine. In the workshop of Geneva (2005), it was clearly established that Telematics is now a natural and important part of Medical Information Systems, particularly in Regional Information Systems. The development of large national projects concerning Patient Shared Records demonstrates also that Telematics is now embedded in most of Medical Information applications.

In 2006 we focused on contacts with other fields of the Medical Information domain through:

- active involvement in the organisation of the workshop in Lille, France (21-24 May 2006) on 'Human Factors Engineering in Medical Informatics', sharing our experiences of usability studies for Hospital Information Systems, Telemedicine, Distant Training, e-Health

- Knut Bernstein (co-chair) participated in the workshop of the IMIA HIS Working group: 'Expanding the Scope of Health Information Systems from Hospitals to Regional Networks, to National Infrastructures, and Beyond', hosted by INA, Instituto Nacional de Administraõ in cooperation with IMIA WG Telematics in Healthcare in Oeiras - Portugal July 2-4, 2006.

Our website will soon be available. It will improve communication on these important topics and disseminate information concerning congresses, workshops and meetings.

\author{
Co-hhair(2005-2007): \\ JytteBrender \\ Dept. of Health Science and Technology \\ Aalborg University, and Virtual Centre for Health Informatics \\ FredrikBaiers Vej7d \\ DK-9220 Aaborg East \\ Dermark \\ Tel: +4545410124 \\ Fax +4545410150 \\ E-mail: :ytte.brender@v-chi.dk
}

\section{Telematics in Health Care}

\author{
Chair (2005-2008): \\ Dr. Regis Beuscart, \\ Professor of Medical Informatics \\ The University of Lille, 1, Place de Verdun \\ 59045 Lille \\ France \\ Tel: +33320526970 \\ Fax: +3320521022 \\ E-mail:bbuscar@@chru-ille.fr
}

Co-chair (2006-2009):

Dr. Knut Bernstein, MD, BA (Informatics)

Consultant, MEDDQ - Medical Informatics and Quality Development

Bronshoi

Copenhagen

Denmakk

Tel: + 4530922272

Email:kb@mediq.dk 